\title{
Short-term impact of dry olive mill residue addition to soil on the resident microbiota
}

\author{
Inmaculada Sampedro ${ }^{a}$, Mariangela Giubilei ${ }^{a}$, Tomas Cajthaml ${ }^{b}$, Ermanno Federici ${ }^{c}$, Federico Federici $^{a}$, \\ Maurizio Petruccioli ${ }^{a}$, Alessandro D'annibale ${ }^{a, *}$ \\ ${ }^{a}$ Dipartimento di Agrobiologia e Agrochimica, University of Tuscia, Via San Camillo De Lellis s.n.c., 01100 Viterbo, Italy \\ ${ }^{\mathrm{b}}$ Laboratory of Environmental Biotechnology, Institute of Microbiology of the ASCR, v.v.i., Prague, Czech Republic \\ ${ }^{\mathrm{c}}$ Dipartimento di Biologia Cellulare ed Ambientale, University of Perugia, Perugia, Italy
}

\section{A R T I C L E I N F O}

\section{Article history:}

Received 1 April 2009

Received in revised form 8 June 2009

Accepted 9 June 2009

Available online 3 July 2009

\section{Keywords:}

Dry olive mill residue

Microbial community profiling

Toxicity

Waste upgrading

\begin{abstract}
A B S T R A C T
The short-term response of the resident soil bacterial and fungal communities to the addition of $5 \%(\mathrm{w} / \mathrm{w})$ of either dry olive mill residue (DOR), DOR treated with Phlebia sp. (PTDOR) or DOR previously extracted with water (WEDOR) was investigated. As opposed to bacteria, the diversity of fungi increased upon the amendments as assessed by denaturing gradient gel electrophoresis of $18 \mathrm{~S}$ rDNA. Over the first 30 days, phospholipid fatty acids analyses indicated a gradual decrease in the relative abundances of $\mathrm{Gram}^{+}$ bacteria (from $44.8 \%$ to $37.9 \%$ ) and a concomitant increase of $\mathrm{Gram}^{-}$bacteria (from $37.3 \%$ to $51.2 \%$ ) in DOR-amended soil. A considerable increase in the fungal/bacterial ratio was observed after 7 days in DOR, WEDOR and PTDOR-amended soils with respect to the control $(0.316,0.165$ and 0.265 , respectively, vs. 0.011 ). The overall microbial activity was stimulated by the amendments as indicated by the higher activity levels of both dehydrogenase and fluorescein diacetate hydrolase. These results indicate that DOR at the application level examined is not toxic on soil microorganisms.
\end{abstract}

(c) 2009 Elsevier Ltd. All rights reserved.

\section{Introduction}

The use of agricultural soils as a sink for organic $C$ is increasingly attracting the attention of the scientific community but its adequacy as a long-term $C$ sequestration strategy is still matter of debate (Mondini and Sequi, 2008). The incorporation of organic wastes into soil, besides being a valuable approach for $\mathrm{C}$ sequestration, may lead to additional benefits, such as prevention of erosion, stabilization of soil aggregates and fertility improvement (Mondini and Sequi, 2008). To this aim, solid residues from olive oil extraction process, such as two-phase olive mill wastes (TPOMW), might be possible candidates (Roig et al., 2006). Among them, the solid residue arising from solvent extraction of residual oil from pomace, generally referred to as dry olive mill residue (DOR), might be more amenable to biological upgrading than other olive mill wastes due to its higher stability to mid-term storage and better textural properties (Roig et al., 2006). In this respect, the high moisture content and the dough-like texture of "alpeorujo", from which DOR arises, have been shown to limit gaseous exchanges thus slowing biodegradation (Cayuela et al., 2006). "Alpeorujo" and DOR share some common properties, such as the high content in cell wall macromolecules (i.e., lignin, cellulose and hemicellulose) associated with

\footnotetext{
* Corresponding author. Tel.: +39 0761 357368; fax: +39 0761357242.

E-mail address: dannib@unitus.it (A. D’annibale).
}

relatively low amounts of nitrogen (0.7-1.8\%); moreover, the presence of anti-microbial compounds is a further determinant for their recalcitrance to biodegradation (Cayuela et al., 2006). The anti-microbial and toxic effects of olive mill wastes have long been known (Paredes et al., 1986) and mainly ascribed to the phenolic fraction (Linares et al., 2003; Sampedro et al., 2008). A better understanding of the diversity of the microbial communities in soils and their response to different agronomic practices, such as amendments with TPOMW, could assist in designing possible pre-treatments of these amendants and subsequent application strategies. To date, the large majority of studies on agronomic use of olive mill wastes, besides being limited to olive mill wastewaters, were conducted by respirometry (Kotsou et al., 2004; Mekki et al., 2006; Saadi et al., 2007), phospholipid fatty acids (PLFA) analyses (Mechri et al., 2007) and cultivation-dependent approaches (Tardioli et al., 1997; Kotsou et al., 2004; Mekki et al., 2006; Di Serio et al., 2008). The latter, however, provided limited information since cultivable microbiota sometimes only represent a minor fraction of the whole community (Amann et al., 1995).

Molecular-based techniques, such as denaturing gradient gel electrophoresis (DGGE; Muyzer et al., 1993), or biomarkers-based approaches, such as PLFA analyses (Baldrian et al., 2008), have given insights into complex environmental communities avoiding the biases associated with laboratory culturing methods. However, none of these methods is devoid of pitfalls and drawbacks; their 